\title{
Lamotrigine-Associated Reversible Severe Hepatitis: A Case Report
}

\author{
Adeline Ngo Su-Yin, MBBS ${ }^{a}$, Winnie W. Tai, PharmD ${ }^{b}$, Kent R Olson, $M D^{b}$
}

aDepartment of Emergency Medicine, Singapore General Hospital, Singapore

bUniversity of California; California Poison Control System, San Francisco Division, San Francisco, CA

\begin{abstract}
Introduction: Anticonvulsant hypersensitivity syndrome is a severe idiosyncratic reaction to antiepileptic drugs. We report a case of a woman with lamotrigine-associated hepatitis who recovered spontaneously with supportive treatment.

Case Report: A 43-year-old woman was being treated with oxcarbazepine for depression and was started on lamotrigine 2 weeks prior to her presentation. The patient then developed nausea and a generalized pruritic macular rash, and was found to have elevated liver enzymes, which peaked at AST, $6079 \mathrm{IU} / \mathrm{L}$; ALT, $6900 \mathrm{IU} / \mathrm{L}$; total bilirubin, $3.9 \mathrm{mg} / \mathrm{dL}(66.7 \mu \mathrm{mol} / \mathrm{L}) ;$ alkaline phosphatase, 149 IU/L; international normalized ration (INR), 1.9. The patient showed no signs of encephalopathy and her clinical examination was essentially normal except for very mild jaundice and a diffuse erythematous pruritic macular rash. The patient was hydrated and managed with supportive care. On the third day of hospitalization, her liver enzymes had improved substantially and she was discharged. At follow-up 1 month later the patient's liver enzymes were within the normal range.

Discussion: We hypothesize that lamotrigine was directly responsible for the patient's rash and liver impairment given the time sequence of drug introduction and resolution of symptoms and liver enzyme abnormality once the drug was withdrawn. The patient suffered severe transaminitis when lamotrigine was added to oxcarbazepine, which resolved after termination of the medication and supportive management. We recommend monitoring the hepatic function in patients who have just been initiated on lamotrigine, especially if they develop jaundice.
\end{abstract}

\section{INTRODUCTION}

Anticonvulsant hypersensitivity syndrome (AHS) is a severe idiosyncratic reaction to antiepileptic drugs [1]. Anticonvulsant hypersensitivity syndromes are typically associated with antiepileptic drugs containing a benzene ring, such as phenytoin, phenobarbital, carbamazepine and lamotrigine. Mucosal and skin involvement feature prominently with lamotrigine use [2]. There are very few reports associating lamotrigine with severe hepatotoxicity [3-8]. We believe this to be the first case reported of a patient with extremely high liver enzymes (AST/ALT > $1000 \mathrm{IU} / \mathrm{L}$ ) when lamotrigine was added to oxcarbazepine treatment, with eventual complete resolution of symptoms and enzyme levels after termination of the medication and supportive management.

\section{CASE REPORT}

A 43-year-old woman with a history of depression, which was being treated with oxcarbazepine twice a day $(300 \mathrm{mg} / \mathrm{morning}$ and $450 \mathrm{mg}$ /evening), was started on lamotrigine 2 weeks prior to her presentation, with the dose increased to $50 \mathrm{mg}$ /day just prior to admission.

Two weeks after starting the lamotrigine, she developed nausea and a generalized pruritic macular rash. She sought treatment in

Keywords: Lamotrigine, hepatitis, adverse drug reaction, drug hypersensitivity

Note: There was no outside funding of any kind used for this study. Corresponding Author: Adeline Ngo, Emergency Department, Singapore General Hospital, Outram Road, Singapore 169608.

Email: angosy@gmail.com 
an emergency department (ED), where she was found to have elevated liver enzymes. The aspartate aminotransferase (AST) was $2764 \mathrm{IU} / \mathrm{L}$, alanine aminotransferase (ALT) was $2490 \mathrm{IU} / \mathrm{L}$, total bilirubin was $0.4 \mathrm{mg} / \mathrm{dL}(6.8 \mu \mathrm{mol} / \mathrm{L})$, and alkaline phosphatase was $93 \mathrm{IU} / \mathrm{L}$. She was instructed to stop all her medications and was discharged with oral antihistamines, and a follow-up appointment was arranged with a primary care physician. Two days later, the patient developed chills, fatigue, and persistent nausea. She sought treatment in an urgent care facility, where the liver enzymes were repeated and showed an alarming elevation: AST, $6079 \mathrm{IU} / \mathrm{L}$; ALT, $6900 \mathrm{IU} / \mathrm{L}$; total bilirubin, $3.9 \mathrm{mg} / \mathrm{dL}$ (66.7umol/L); alkaline phosphatase, $149 \mathrm{IU} / \mathrm{L}$; international normalized ration (INR), 1.9; prothrombin time, 21.5 seconds; creatinine, $0.7 \mathrm{mg} / \mathrm{dL}$ (61.9 $\mu \mathrm{mol} / \mathrm{L})$; white cells $5.3 \times 103 / \mathrm{L}$ (7\% eosinophils); platelets 219 x 103/L; hemoglobin, $14.0 \mathrm{~g} / \mathrm{dL}$; hematocrit, 41\%; albumin, $3.8 \mathrm{~g} / \mathrm{dL}$; blood urea nitrogen, $8 \mathrm{mg} / \mathrm{dL}$ (2.9 mmol/L). Serology tests for hepatitis A, B, and C were negative. Cardiac enzymes were normal. Abdominal ultrasound was obtained, which was normal. The patient denied taking any mushrooms, herbs, or any other medications other than lamotrigine and oxcarbazepine in the prescribed manner. She did not have any recent travel and she had no history of alcohol or recreational drug abuse. She was not known to have any allergic tendencies or previous drug allergies.

The patient showed no signs of encephalopathy. Her vital signs were normal and there was no fever. Clinical examination was essentially normal except for very mild jaundice and a diffuse erythematous pruritic macular rash. There were no intraoral lesions, lymphadenopathy, or hepatosplenomegaly. Although the patient did not feel ill, she was admitted for observation and investigation.

Management included intravenous hydration and supportive care. She did not have any clinical signs or symptoms of bleeding but was started prophylactically on oral vitamin $\mathrm{K}$ and a proton pump inhibitor (Protonix). An antihistamine (diphenhydramine) was prescribed for symptomatic relief of her itching. No systemic steroids were prescribed.

On the third day of hospitalization, her liver enzymes had improved substantially and she was discharged: AST, $1676 \mathrm{IU} / \mathrm{L}$; ALT, 3907 IU/L; INR, 1.2; prothrombin time, 15.3 seconds. The patient discontinued all her medications after discharge.

At follow-up 1 month later, the patient's liver enzymes were within the normal range: AST, 27 IU/L; ALT, 69 IU/L; INR, 1.1; prothrombin time, 14.0 seconds.

\section{DISCUSSION}

AHS is a type of drug hypersensitivity syndrome involving anticonvulsants [1]. While it occurs in only a small proportion of patients, it is associated with considerable morbidity and even mortality [2].

Lamotrigine is an anticonvulsant that inhibits voltagedependent sodium channels, thereby stabilizing neuronal membranes and reducing the release of excitatory neurotransmitters, particularly glutamate and aspartate [9]. It has antidepressant efficacy [10] and has been used for managing bipolar depression [11].

We report a woman with lamotrigine-associated hepatitis who recovered spontaneously with supportive treatment. We believe that this is the first reported case of severe acute hepatitis when lamotrigine was added to oxcarbazepine in the treatment of a depressed patient.

We hypothesize that lamotrigine was directly responsible for the patient's rash and liver impairment given the time sequence of drug introduction and resolution of symptoms and liver enzyme abnormality once the drug was withdrawn.

The patient had been taking oxcarbazepine without any complications for the past year. She developed symptoms 2 weeks into her therapy with lamotrigine, which is the classic indication of AHS $[1,2]$. There was a documented significant rise in liver enzymes within 2 days and recovery of liver function when the anticonvulsants were stopped. Her only symptoms were nausea and a diffuse erythematous macular rash. Previous case reports [3-8] of lamotrigine-induced AHS with severe hepatotoxicity have described fever and some signs of encephalopathy or hepatic decompensation. Our patient did not have any fever and was mentally and neurologically normal, which was unlike most previously reported patients with severe hepatic involvement.

The greatest risk of rash appears to be during the first 8 weeks of treatment [12]. The overall rate of rashes for patients taking lamotrigine is $13 \%$ [12]; any rash in such patients is potentially serious and should be evaluated promptly [13]. Although the patient was sent home after her initial visit to the ED, relying on outpatient treatment with antihistamines or corticosteroids is inadequate and not recommended, as the role of these agents are uncertain [14].

In a systematic review of 26 patients with lamotrigine-associated AHS [15], lamotrigine was being used concomitantly with other antiepileptic drugs such as carbamazepine or valproate. This patient was taking oxcarbazepine, a structural derivative of carbamazepine [16]. There have not been any previous reports of oxcarbazepine-associated hepatitis or hepatic failure in an adult. There was, however, a case of a child with an acute severe hepatitis associated with oxcarbazepine use [17]. However, the temporal course (onset after addition of lamotrigine) made the association of AHS with oxcarbazepine unlikely, although the concomitant anticonvulsant administration may have interacted with lamotrigine metabolism.

In a retrospective evaluation, the influence of oxcarbazepine on lamotrigine serum concentrations was investigated [18]. Administration of oxcarbazepine decreased lamotrigine serum concentrations by approximately $29 \%$ due to the inducing effect of oxcarbazepine on lamotrigine. This could lead to an accumulation of its metabolites, which in turn may precipitate the immune reaction. In another study, lamotrigine increased concentrations of the active 10-mono-hydroxy metabolite of oxcarbazepine [19]. It is unknown if these changes in concentration are clinically important, although it may be necessary to adjust the dose of oxcarbazepine when starting, stopping, or changing 
the dose of oxcarbazepine. However, the dosage of medication is irrelevant if the hepatitis was due to a hypersensitivity reaction.

There was no serological evidence of viral hepatitis or any history of use of other hepatotoxic drugs, or ingestion of herbal medicine or mushrooms. Hepatotoxicity during lamotrigine therapy was also thought to be related to a specific patient profile such as systemic complications or status epilepticus [5], but our patient had no prior history of drug or alcohol abuse and no other medical history such as liver impairment. She had no seizures or evidence of rhabdomyolysis. There was no other significant intervention done other than supportive and symptomatic management. Although oral corticosteroids have been used with good outcome in case reports [20,21], our patient made an uneventful recovery with supportive care, and systemic steroids were never started.

It may be prudent to monitor the hepatic function in patients who have just been initiated on lamotrigine if they develop jaundice, especially if they are also taking another anticonvulsant. In such an event, the immediate discontinuation of the medication should be accompanied by vigorous resuscitation and supportive care to prevent further morbidity or mortality [6].

\section{CONCLUSION}

We believe this to be the first case reported of a patient with severe transaminitis (AST/ALT >1000 IU/L) when lamotrigine was added to oxcarbazepine, which resolved after termination of the medication and supportive management.

Concomitant antiepileptic drug with lamotrigine may increase the risk of AHS.

Relying on outpatient treatment with antihistamines or corticosteroids is inadequate; it may be prudent to monitor the hepatic function in patients who have just been initiated on lamotrigine, especially if they develop jaundice.

The authors have no potential financial conflicts of interest to report.

\section{REFERENCES}

1. Shear NH, Spielberg SP. Anticonvulsant hypersensitivity syndrome. In vitro assessment of risk. J Clin Invest 1988;82(6): 1826-1832.

2. Sullivan JR, Shear NH. The drug hypersensitivity syndrome: what is the pathogenesis? Arch Dermatol 2001;137(3):357-364.

3. Mecarelli O, Pulitano P, Mingoia M, Ferretti G, Rossi M, Berloco PB, et al. Acute hepatitis associated with lamotrigine and managed with the molecular adsorbents recirculating system (Mars). Epilepsia 2005;46(10):1687-1689.

4. Overstreet K, Costanza C, Behling C, Hassanin T, Masliah E. Fatal progressive hepatic necrosis associated with lamotrigine treatment: a case report and literature review. Dig Dis Sci 2002;47(9):1921-1925.

5. Fayad M, Choueiri R, Mikati M. Potential hepatotoxicity of lamotrigine. Pediatr Neurol 2000;22(1):49-52.
6. Arnon R, DeVivo D, Defelice AR, Kazlow PG. Acute hepatic failure in a child treated with lamotrigine. Pediatr Neurol 1998;18(3):251-252.

7. Makin AJ, Fitt S, Williams R, Duncan JS. Fulminant hepatic failure induced by lamotrigine. BMJ 1995 29;311(7000):292.

8. Schaub JE, Williamson PJ, Barnes EW, Trewby PN. Multisystem adverse reaction to lamotrigine. Lancet 1994;13;344(8920):481.

9. Brodie MJ. Lamotrigine. Lancet 1992;339:1397-1400.

10. Calabrese JR, Bowden CL, Sachs GS, Ascher JA, Monaghan E, Rudd GD. A double-blind placebo-controlled study of lamotrigine monotherapy in outpatients with bipolar I depression Lamictal 602 Study Group. J Clin Psychiatry 1999;60:79-88.

11. Calabrese JR, Bowden CL, Sachs G, Yatham LN, Behnke K, Mehtonen OP. A placebo-controlled 18-month trial of lamotrigine and lithium maintenance treatment in recently depressed patients with bipolar I disorder. J Clin Psychiatry 2003;64:1013-1024.

12. Calabrese JR, Sullivan JR, Bowden CL, Suppes T, Goldberg JF, Sachs GS, et al. Rash in multicenter trials of lamotrigine in mood disorders: clinical relevance and management. J Clin Psychiatry 2002;63(11):101-129.

13. Guberman AH, Besag FM, Brodie MJ, Dooley JM, Duchowny MS, Pellock JM, et al. Lamotrigine-associated rash: risk/benefit considerations in adults and children. Epilepsia 1999;40(7):985-991.

14. Faught E, Morris G, Jacobson M, French J, Harden C, Montouris $\mathrm{G}$, et al. Adding lamotrigine to valproate: incidence of rash and other adverse effects: Postmarketing Antiepileptic Drug Survey (PADS) Group. Epilepsia 1999;40(8):1135-1140.

15. Schlienger RG, Knowles SR, Shear NH. Lamotrigine-associated anticonvulsant hypersensitivity syndrome.Neurology 1998;51(4):1172-1175.

16. Kearney TE: Carbamazepine and oxcarbazepine. In: Olson KR, ed. Poisoning and Drug Overdose, 5th ed. International: McGraw-Hill Lange 2007:148-150.

17. Bosdure E, Cano A, Roquelaure B, Reynaud R, Boyer M, Viard L, et al. Oxcarbazepine and DRESS syndrome: a paediatric cause of acute liver failure. Arch Pediatr 2004;11(9):1073-1077.

18. May TW, Rambeck B, Jurgens U. Influence of oxcarbazepine and methsuximide on lamotrigine concentrations in epileptic patients with and without valproic acid comedication: results of a retrospective study. Ther Drug Monit 1999;21(2):175-181.

19. Guenault N, Odou P, Robert H. Increase in dihydroxycarbamazepine serum levels in patients co-medicated with oxcarbazepine and lamotrigine. Eur J Clin Pharmacol 2003;59(10):781-782.

20. Schaub N, Bircher AJ. Severe hypersensitivity syndrome to lamotrigine confirmed by lymphocyte stimulation in vitro. Allergy 2000;55(2):191-193.

21. Chang CC, Shiah IS, Yeh CB, Wang TS, Chang HA. Lamotrigine-associated anticonvulsant hypersensitivity syndrome in bipolar disorder. Prog Neuropsychopharmacol Biol Psychiatry 2006;30(4):741-744. 